\title{
Parallel transjugular intrahepatic portosystemic shunt (TIPS) for TIPS dysfunction: technical and patency outcome
}

\author{
Mohamed S. Alwarraky ${ }^{1 *}$, Hasan A. Elzohary², Mohamed A. Melegy² and Anwar Mohamed²
}

\begin{abstract}
Background: Several methods have been used in treating TIPS dysfunction, including balloon angioplasty with/ without telescoping stent. However, there are some cases refractory to recanalization and parallel shunt (PS) should be tried. The aim is to evaluate the technical and patency outcomes of the PS. We retrospectively reviewed the medical records of patients $(n=37)$ with refractory TIPS dysfunction who were managed by PS. All clinical, laboratory, and technical data as well as radiological data over 1 year were collected. Technical success was the primary outcome while complications and shunt patency were the secondary outcomes.

Results: Thirty-three out of the 37 patients (89.2\%) of the study were Budd-Chiari syndrome cases. Caval puncture was done in 34/37 (91.9\%) of cases while the hepatic vein puncture was done in 3/37 cases (8.1\%). Portal entry through the left branch was done in 22 patients (59.5\%), from neck of PV in 13 patients (35.1\%) to right PV in 2 patients (5.4\%). Technical success was achieved in 100\% of cases. Porto-systemic pressure gradient (PSG) before PS insertion was $32.5 \pm 8.1 \mathrm{mmHg}$ and it became $8.9 \pm 2.3 \mathrm{mmHg}$ after the PS insertion $(P<0.01)$. The median primary patency duration was 11 months. The estimated 12 and 18 months primary patency rates were $32 / 37(86.5 \%)$ and (78.4\%) respectively. Intra-procedure complications occurred in 8 patients (21.6\%) and were successfully treated medically. Acute PS thromboses occurred in 4 patients (10.8\%) and required early successful interventions.
\end{abstract}

Conclusion: It is proven from this study that patients with refractory TIPS occlusion have another chance for a second PS to treat portal hypertension symptoms. Moreover, the PS is a durable, safe, and effective treatment on mid-term basis.

Keywords: Transjugular intrahepatic portosystemic shunt, Parallel shunt, Revision, Refractory occlusion

\section{Background}

Trans-jugular intrahepatic portosystemic shunt (TIPS) was clinically introduced in 1989 and known since then that is an effective and safe procedure in the management of complicated portal hypertension $\left[\begin{array}{ll}1, & 2] \text {. }\end{array}\right.$

\footnotetext{
* Correspondence: drwarraky@yahoo.com

'Department of Diagnostic and Interventional Imaging, National Liver Institute, Menoufia University, Yassin Abdelghaffar St., Shebin Al-Kom, Menoufia, Egypt

Full list of author information is available at the end of the article
}

Nevertheless, a major drawback of TIPS placement is stent dysfunction, resulting in recurrence of clinical symptoms or complications and requiring subsequent, and sometimes repeated, endovascular procedures for recanalization [3, 4]. Many factors cause stent dysfunction including acute thrombotic events within the stent itself, pseudo-intimal hyperplasia in the TIPS parenchymal tract, or intimal hyperplasia in the outflow of hepatic vein [5-7].

\section{Springer Open}

(c) The Author(s). 2020 Open Access This article is licensed under a Creative Commons Attribution 4.0 International License, which permits use, sharing, adaptation, distribution and reproduction in any medium or format, as long as you give appropriate credit to the original author(s) and the source, provide a link to the Creative Commons licence, and indicate if changes were made. The images or other third party material in this article are included in the article's Creative Commons licence, unless indicated otherwise in a credit line to the material. If material is not included in the article's Creative Commons licence and your intended use is not permitted by statutory regulation or exceeds the permitted use, you will need to obtain permission directly from the copyright holder. To view a copy of this licence, visit http://creativecommons.org/licenses/by/4.0/. 
The use of ePTFE-covered stent grafts improved the long term stent patency markedly by avoiding pseudointimal hyperplasia. However, the reported primary patency rates of ePTFE-covered stent at 2, 4, and 6 years were $74 \%, 62 \%$, and $50 \%$ respectively $[8,9]$.

To manage TIPS dysfunction, several modalities of recanalizations were used including thrombolysis, thrombo-suction, balloon angioplasty, and in-stent insertion. Many approaches were used to negotiate the obstructed index TIPS to achieve recanalization [10, 11]. In spite of these numerous recanalization modalities, there are refractory cases where the obstructed/ stenotic stents are not inaccessible, impassable, or amenable for recanalization [12]. In such cases, the creation of another PS is necessary and is considered as the last treatment option to regain the portal decompression.

The aim of our study is to evaluate the technical and patency outcomes of the PS.

\section{Methods}

\section{Study design and patients population}

We retrospectively reviewed the medical records of all consecutive adult patients $(n=288)$ who underwent recanalization procedures $(n=756)$ for the treatment of index TIPS dysfunction in our hospital between 2008 and 2018. The clinical and radiological data were retrieved for all the patients. Two hundred and fifty-one patients were excluded because they underwent successful recanalization procedures for their index TIPS. The remaining 37 adult patients who were subjected to PS insertion were included in our study. Figure 1 shows the flowchart of the numbers of included and excluded patients.

Indications for the index TIPS creation in the studied patients were (1) recurrence of ascites from BuddChiari syndrome in 33 patients; (2) recurrence of refractory ascites from post-hepatitis cirrhosis of 4 patients; and (3) recurrence of variceal bleeding in 1 patient. The indications of primary TIPS were the same as those of PS. All index TIPS cases were done with bare stents.

\section{Technique of PS insertion}

Parallel shunt was created using the classic technique of TIPS that has been described previously [13, 14]. All studies were used under a fluoroscopic guidance machine (Allura Xper FD20; Philips Healthcare; Philips). After mild intravenous sedation and analgesia (50 to $100 \mathrm{mg}$ of meperidine and 1 to $5 \mathrm{mg}$ of midazolam), a puncture needle was advanced from the transjugular vein through the IVC. We used the right jugular vein in 34 (91.9\%) patients while the left jugular vein was used in $3(8.1 \%)$ patients.

Puncture of the parenchyma was done from the IVC in 33 patients and from the middle hepatic or Rt. hepatic in 4 patients using the metal TIPS needle of RUPS-100 (Cook Inc., Bloomington, IL, USA). Once the needle got

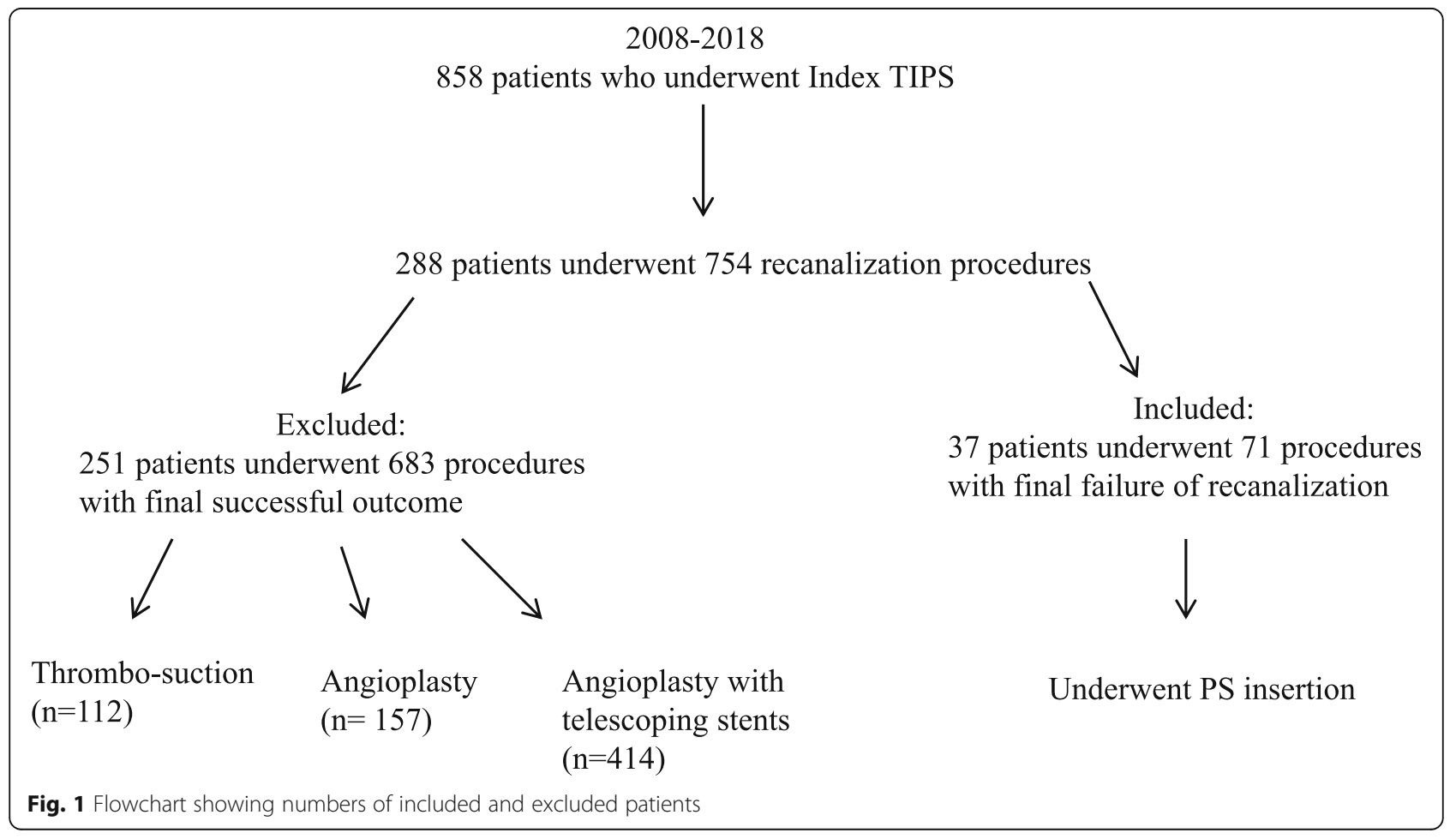


inside the parenchyma, it was directed to puncture the PV (PV). Portal entry was confirmed when tactile sensation and suction of blood while the needle is withdrawn. Once punctured, a 5-Fr Cobra catheter (Imager II, Boston Scientific, USA) was then introduced into the lumen of the main PV. Portography was then performed to outline the anatomy of the portal circulation and the location of the index stent.

Dilation of the parenchymal tract was done using 5 or $6 \mathrm{~mm}$ angioplasty balloon (Ultra-Thin Diamond ${ }^{\mathrm{mm}}$ or Mustang ${ }^{\mathrm{Tm}}$ 0.035" Balloon Dilatation Catheter; Boston Scientific). Following parenchyma dilatation, the bare Wallstents (Medinvent, Schneider, Bülach, Switzerland) were implanted then dilated gradually. If the PSG was still high, we increased dilatation incrementally. The endpoint of the PSG was to be below $12 \mathrm{mmHg}$. More than one stents were implanted to cover the whole length of the parenchyma from PV up to the IVC. Finally, a shunt venography was performed to confirm shunt patency with flow of contrast to cava and heart. Intravenous heparin (3000 U) was administered immediately after successful PS creation. Post-operatively, anti-coagulants combined with anti-platelets were prescribed for a year. Doses of anti-coagulants were adjusted according to INR level of $2-3.5$.

\section{Data collection}

All clinical, technical, laboratory, index TIPS, and radiological data over the study period were collected. Technical data, hemodynamic parameters before and after PS insertion, PS dysfunction, re-interventions, and complications were collected and tabulated. When PS dysfunction was suspected by Doppler or symptom recurrence, the patient had to undergo revision with angiography and managed either by the proper modality of recanalization.

\section{Study endpoints and definitions}

The endpoints of the present study were the technical success, stent patency time as well as rate at 12 and 18 months, and complications. Technical success was defined as a correct positioning and deployment of the Wallstent parallel to the index TIPS with angiographic evidence of patency and drop of PSG to below $12 \mathrm{mmHg}$. PS dysfunction was defined as the angiographic narrowing more than 50\%, increased PSG higher than the baseline or both. PS patency was defined as the time interval between PS creation and stent dysfunction or patient death while having a patent stent. The stent was assumed to be patent at the time of death if there was no evidence of stent dysfunction. Complications considered were intraprocedure complications, and early complications occurring in the first 7 days of the procedure. Procedure-related major and minor complications were defined as previously reported [39], and treated accordingly. The complications did not include stent dysfunction which was recorded and analyzed separately.

\section{Statistical analysis}

Data entry, processing, and statistical analysis were carried out using Microsoft Excel 2007 (Microsoft Corporation, NY, and the USA) and SPSS (Statistical Package for the Social Science; SPSS Inc., Chicago, IL, USA) version 22 for Microsoft Windows. Quantitative data were described in terms of mean \pm standard deviation $( \pm S D)$, while qualitative data were expressed as frequencies (number of cases) and relative frequencies (percentages). Comparisons between quantitative variables were done using unpaired Student's $t$ test for parametric data or Mann-Whitney rank-sum test for non-parametric data. Chi-square test was performed for categorical variables. A probability value ( $p$ value) less than 0.05 was considered statistically significant.

\section{Results}

\section{Technical and hemodynamic outcomes}

Clinical and technical data of the patients are summarized in Table 1 . They were 8 (21.6\%) males and 29 (78.4\%) females, age ranged between (18-43 years) mean age $21.8 \pm 7.8$ years. The original liver disease underlying these cases were Budd-Chiari syndrome ( $n$ $=33$ ) and hepatitis $C$ cirrhosis $(n=4)$. According to Child's classification, $4(10.8 \%)$ patients were class A, 32 patients $(86.5 \%)$ were class $\mathrm{B}$, and one patient belonged to class $\mathrm{C}$ disease. All the patients were subjected to recanalization procedures before PS and these were 71 procedures. The median patency time of the index TIPS was 9.7 months (range, 5-19 months). Median interval to last refractory occlusion was 18 months.

Technical success of PS creation with Wallstents was achieved in all 37 patients (100\%). Puncture of the parenchyma was done from the IVC in 34 (91.9\%) patients, and from the middle hepatic or right hepatic in 3 (8.1\%) patients. The target point in the PV was the neck in 13 (35.1\%) patients (Figs. 2, 3, and 4), the left branch in 22 (59.5\%) patients (Figs. 1, 5, 6, and 7), and the right branch in $2(5.4 \%)$ patients. The mean number of trials to puncture the PV was $11 \pm 4$ trials. The mean time to occlusion was $26 \pm 12$ days.

The mean PSG decreased significantly from $32.5 \pm 8.1$ $\mathrm{mmHg}$ (range, $26-47 \mathrm{mmHg}$ ) to $8.9 \pm 2.3 \mathrm{mmHg}$ (range, $4-14 \mathrm{mmHg})$ after PS creation $(P<0.001)$. In 34 patients (91.9\%), it was necessary to deploy two Wallstent 
Table 1 Clinical and technical data of the patients

\begin{tabular}{|c|c|}
\hline Parameter & \\
\hline Age (years) & $21.8 \pm 7.8$ \\
\hline Range & $18-43$ \\
\hline \multicolumn{2}{|l|}{ Gender $(n)(\%)$} \\
\hline Male & $8(21.6 \%)$ \\
\hline Female & $29(78.4 \%)$ \\
\hline \multicolumn{2}{|l|}{ Child (n) } \\
\hline A & $4(10.8 \%)$ \\
\hline B & $32(86.5 \%)$ \\
\hline C & $1(2.7 \%)$ \\
\hline \multicolumn{2}{|l|}{ Indications of TIPS (n) (\%) } \\
\hline Budd-Chiari syndrome & $33(89.2 \%)$ \\
\hline Refractory ascites & $3(8.1 \%)$ \\
\hline Recurrent bleeding & $1(2.7 \%)$ \\
\hline \multicolumn{2}{|l|}{ Index TIPS parameters } \\
\hline Median interval to last occlusion (months) & 18 \\
\hline Number of re-interventions & 71 \\
\hline \multicolumn{2}{|l|}{ Approach (n) (\%) } \\
\hline Right internal jugular vein & $34(91.9 \%)$ \\
\hline Left internal jugular vein & $3(8.1 \%)$ \\
\hline \multicolumn{2}{|l|}{ Puncture entry } \\
\hline Trans-caval puncture & $34(91.9 \%)$ \\
\hline Hepatic vein puncture & $3(8.1 \%)$ \\
\hline \multicolumn{2}{|l|}{ Portal entry } \\
\hline Left PV & $22(59.5 \%)$ \\
\hline Neck of the PV & $13(35.1 \%)$ \\
\hline Right PV & $2(5.4 \%)$ \\
\hline \multicolumn{2}{|l|}{ No. of stents } \\
\hline Two telescoping stents & $34(91.9 \%)$ \\
\hline One stent & $3(8.1 \%)$ \\
\hline Number of trial to reach $\mathrm{PV}(\mathrm{M} \pm \mathrm{SD})$ & $11 \pm 4$ \\
\hline PSG $(\mathrm{mmHg})$ before PS insertion $(\mathrm{M} \pm \mathrm{SD})$ & $32.5 \pm 8.1$ \\
\hline PSG $(\mathrm{mmHg})$ after PS insertion $(\mathrm{M} \pm \mathrm{SD})$ & $8.9 \pm 2.3$ \\
\hline
\end{tabular}

endoprostheses to cover the parenchymal tract till $1 \mathrm{~cm}$ in the cava. In the other 3 patients, a single Wallstent was used.

\section{Shunt patency}

The patency parameters of the patients are summarized in Table 2. After a mean follow-up of $26 \pm 8$ months, 8 patients (11.2\%) experienced PS dysfunction. Initial symptoms of dysfunction were recurrent $(n=4)$, abdominal pain $(n=2)$, and decreased diuresis $(n=2)$. During the same study period, these 8 patients underwent 10 angiographic examinations for suspected PS dysfunction. Causes of PS dysfunctions were shunt thrombosis $(n=$
7) and pseudo-intimal hyperplasia $(n=3)$. All dysfunctions led to PS revision by thrombo-suction, thrombus defragmentation, or balloon angioplasty alone. Median duration of patency (month) was 16 (19-9) months. The median interval between PS placement and the first dysfunction was $11.8 \pm 7.8$ months. The estimated 12 months primary patency rate $32 / 37$ (86.4\%), and 18 months primary patency rate was $30 / 37$ (77.7\%). The median primary patency duration was 16 months. All first PS dysfunctions occurred within the first 12 months.

\section{Complications}

Table 3 shows the complications in our series. The procedures passed safely in 29 patients (78.4\%) with no intra-procedure complications. Intra-procedure complications occurred in 8 patients $(21.6 \%)$ and included inadvertent biliary puncture in $2 / 37$ patients (5.4\%), intraperitoneal bleeding from capsule injury in 3 patients (8.1\%), acute intra-procedure PS thrombosis in one patient $(2.7 \%)$, transient and marked bradycardia in 1 patient $(2.7 \%)$, and transient respiratory distress $(n=1)$. All the intra-procedure complications were successfully managed by conservative treatment. Early complications (i.e., 7 days after the end of the procedure) with acute PS thromboses occurred in 4 patients (10.8\%). These thromboses were managed successfully by early PS revision with a combination of thrombo-aspiration and dilatation. No recorded cases of hepatocellular carcinoma, encephalopathy, or acute liver failure as late complications.

\section{Discussion}

Transjugular intrahepatic porto-systemic shunt is a commonly used effective procedure in managing cases with complicated portal hypertension with a limitation of being frequently dysfunctional. Other secondary interventions are made to overcome the problem of TIPS dysfunction. TIPS dysfunction may occur due to one of the following reasons: acute thrombosis of the stent, pseudo-intimal hyperplasia, secondary to biliary leaks into the shunt lumen, and intimal hyperplasia in the outflow hepatic vein or inflow PV [15]. Also, the position of the stent within the outflow hepatic vein affects strongly TIPS patency. Blood turbulence and shear stress with increased shunt flow can accelerate pseudo-intimal hyperplasia and lead to shunt dysfunction. Some studies demonstrated that when TIPS extends to hepatocaval junction, it has a better patency rate than when introduced in the hepatic vein [16].

Several interventional modalities have been used to overcome dysfunctional TIPS, including angioplasty and placement of telescoping stent. The best option is the placement of an additional in-stent or 


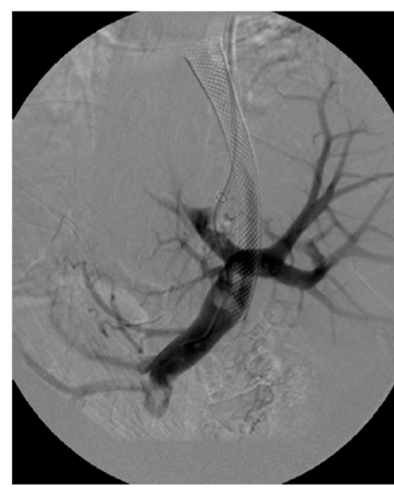

a

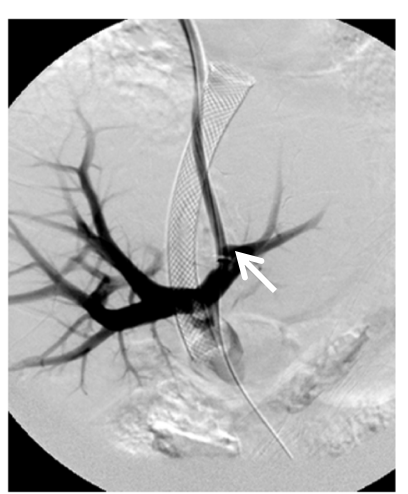

b

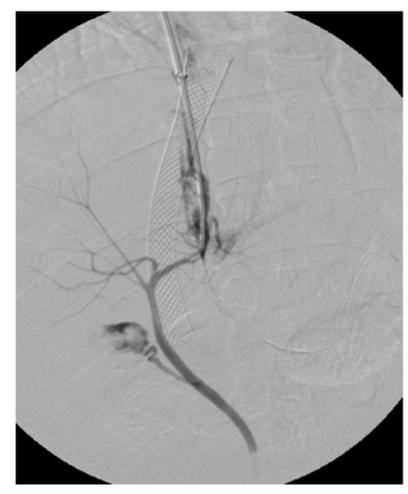

C

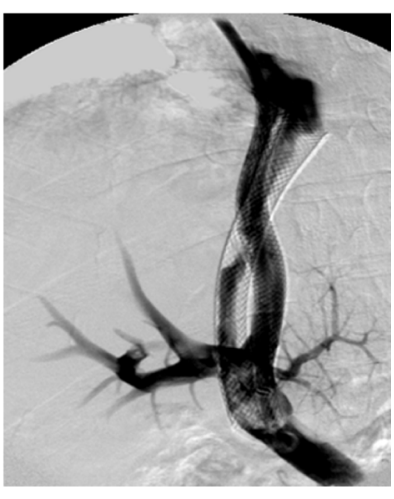

d

Fig. 2 A 25-year-old female with Budd-Chiari and occluded index TIPS. Puncture of the portal vein was done from the left PV (arrow) and the portogram in lateral (a) and AP (b) views show occluded index TIPS. Injury of the left bile duct is seen with contrast filling the biliary system (c). Final portogram after insertion of PS showed complete patency with good shunting of contrast to cava (d)

telescoping stent after negotiating the site of shunt stenosis or occlusion. This method not only allows for the restoration of the TIPS functions, but it may also be related to the improved shunt patency aided by the reinforcement and the radial strength of the second stent [16]. But if stenotic or occluded shunt appears inaccessible, impassable, or non-amenable to dilatation, the creation of another PS is necessary.

Trans-caval puncture was first described by Haskal et al. in 1996 with cases of inaccessible hepatic veins or in cases where the caudal locations of PV bifurcation were close to hepatic veins [3]. In the study of Luo et al. on 18 patients, they used the trans-caval approach which was difficult in one patient with Budd-Chiari syndrome [17]. In our study, we performed trans-caval puncture on (33/37) (89.2\%) patients with Budd-Chiari syndrome and another one with blocked previous shunt and inaccessible hepatic veins. Trans-caval approach was particularly difficult in our patients because the index TIPS was done using the same trans-caval approach making the cava room for the second PS narrower with limited needle control.

Regarding the portal entry, no studies have described the point of entry to the PV although it is a critical point in PS insertion. Because the index TIPS often occupies the right branch PV, the chance to go to PV is limited from the same vein. In our study, we punctured the left PV in 22 patients (59.5\%) while we punctured the neck in 13 patients (35.1\%) (Fig. 7), and we punctured the right PV in 2 patients. Puncturing the left portal is very difficult because of 2 factors: the first one is that the location is more anterior than that of the right one necessitating bending of

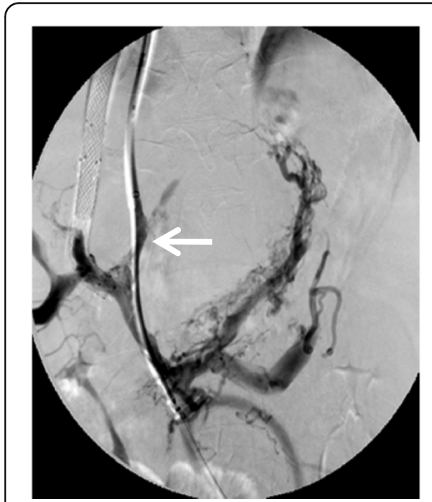

a

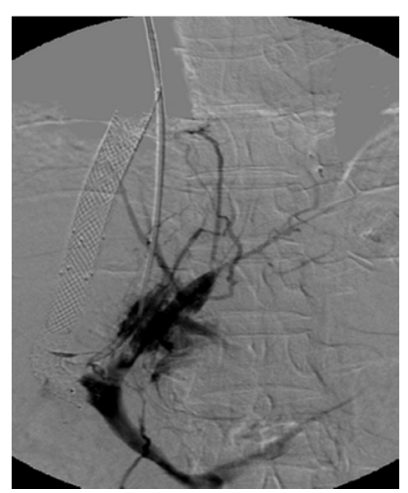

b

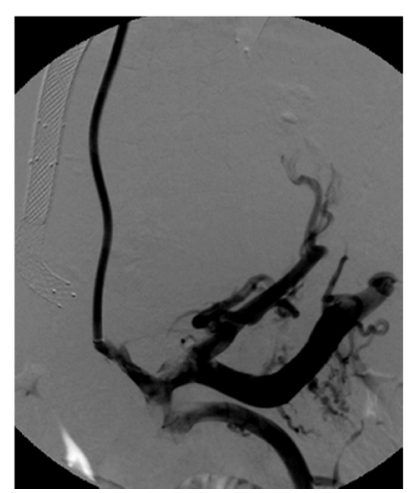

C

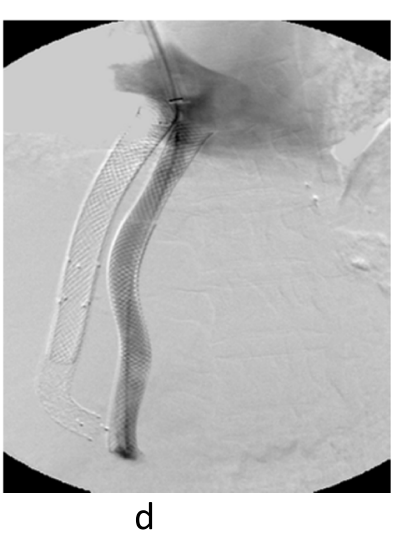

d

Fig. 3 A 41-year-old male presented with recurrent ascites due to occluded TIPS for Budd-Chiari syndrome. Puncture of the portal vein was done from the left PV and portogram (arrow) (a). However, hematoma developed from multiple punctures (b). Portography was done with retrograde filling of the left gastric, splenic, and superior mesenteric veins (c). Final portogram after insertion of PS showed good flow through the shunt with absence of the retrograde filling of the portal tributaries (d) 


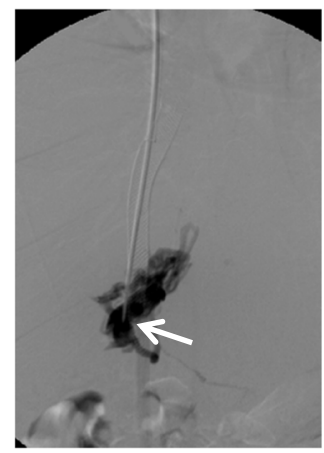

a

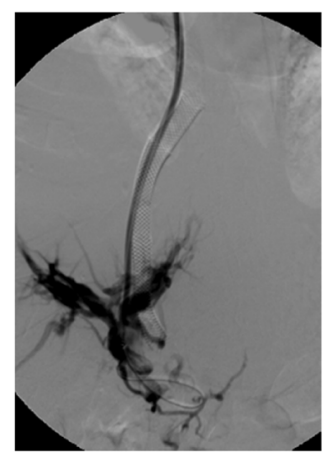

b

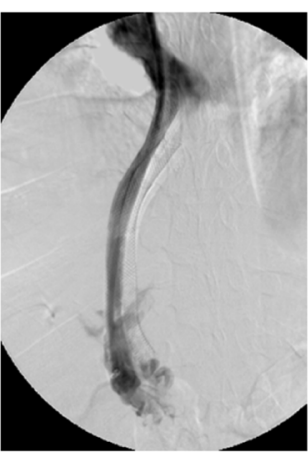

C

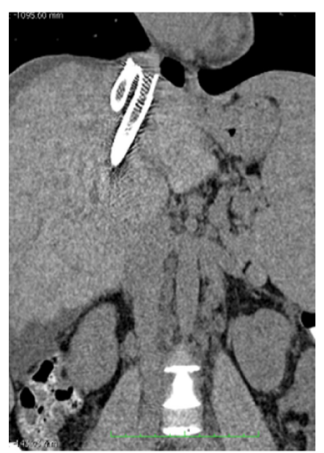

d

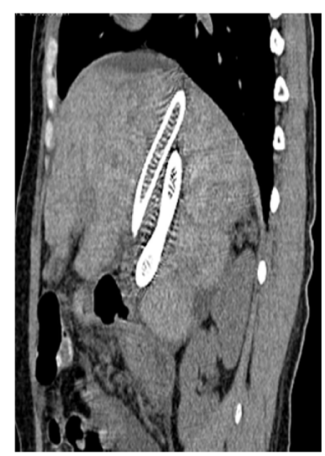

e

Fig. 4 A 36-year-old female with occluded TIPS for Budd-Chiari. Puncture of the portal vein was done from the base of the left PV (arrow) (a). Portography was done with opacification of both PV branches without the stent (b). Final portogram after insertion of PS showed good shunting of contrast from the portal to the cava, with no flow in the index shunt (c). Reconstructive images in coronal (d) and sagittal (e) planes showed the anatomical relations of both stents inside the liver tissue

the TIPS needle up to 90 degrees. The second one is the short cranio-caudal distance between top of cava to left PV compared to the right PV.

In 1998, Dabos et al. first described a series of 29 patients undergoing the PS insertion, suggesting that the PS patency without further intervention is slightly superior to the patency of the first shunts [18]. In 2006, Helmy et al. described the natural history of PS in 40 patients with the TIPS insufficiency. After a mean follow-up period of 11.6 months, both the PS and the index shunt in the non-PS group behaved in a similar way regarding the cumulative primary shunt patency rates at $6,12,24$, and 36 months $(60.3 \%$, $33.6 \%, 22.4 \%$, and $7 \%$ vs. $65.1 \%, 46.1 \%, 18.5 \%$, and 8.5\%) [19].

It is noteworthy that following the previously mentioned studies, one publication of case series and limited case report studies were published [20-22]. Luo et al. reported the outcome of 18 patients with portal hypertension with PS insertion. All of the patients included in their study were cirrhotic except one patient complaining of Budd-Chiari syndrome. They used Wallgraft in 10

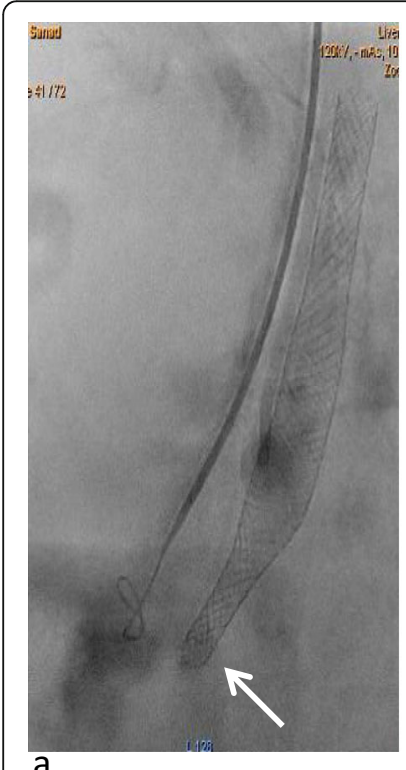

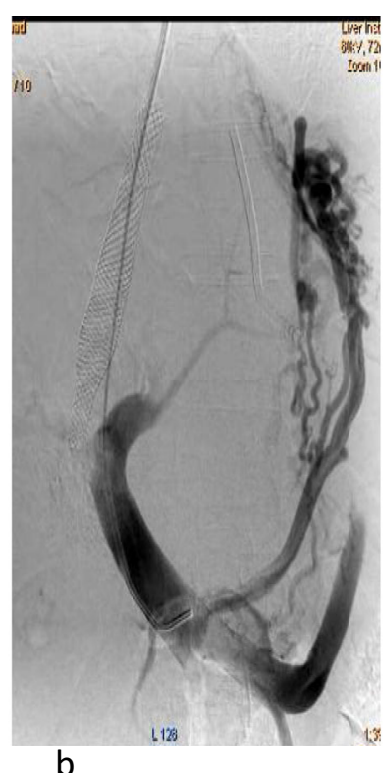

b

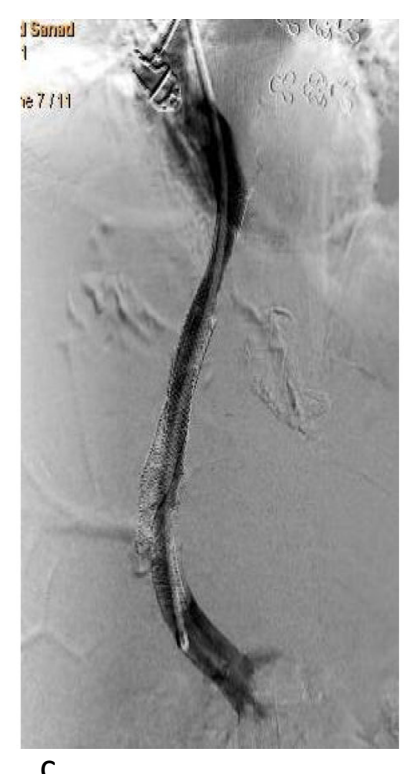

C

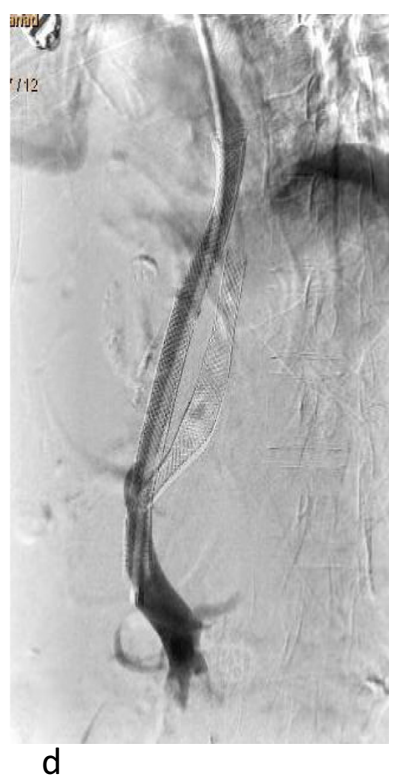

d

Fig. 5 A 29-year-old man following TIPS creation for Budd-Chiari with recurrent ascites. The TIPS needle is inserted anteriorly to index TIPS that showed compressed inflow end (arrow) (a). Puncture of the PV was done at the neck and portography shows opacification of the left gastric and splenic veins with collaterals. Final portogram (b). PS insertion, in AP view (c) and lateral (d) views, showed widely patent PS showing good flow through shunt, without opacification of collateral veins 


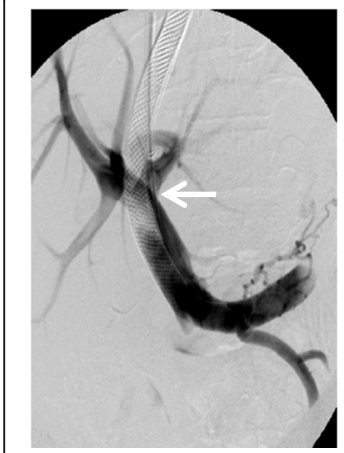

a

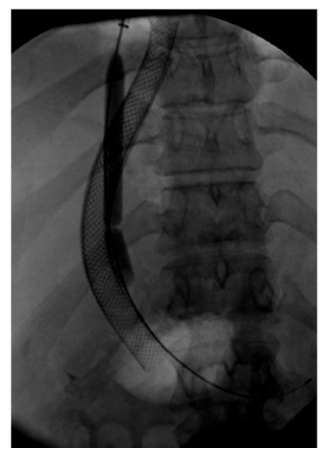

b

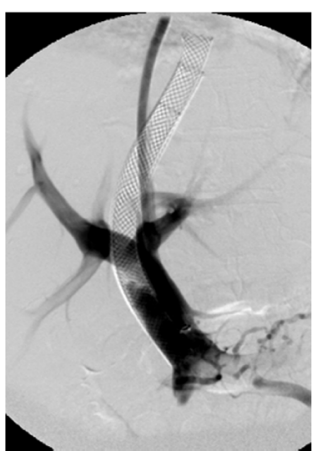

C

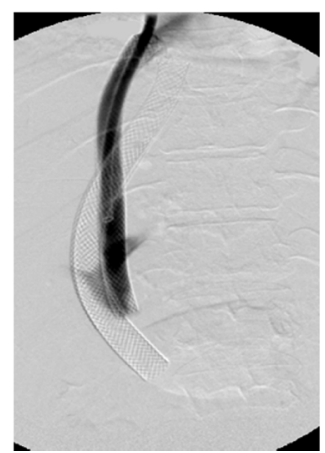

d

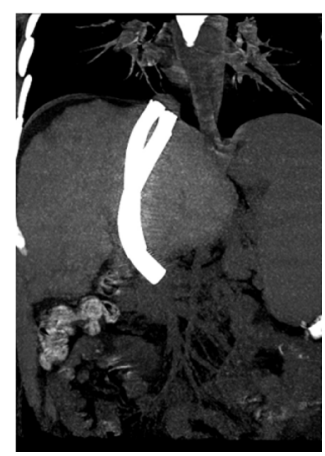

e

Fig. 6 A 38-year-old female with Budd-Chiari and occluded index TIPS (previous 3 telescoping stents). Initial portal puncture was done at portal neck (arrow) and portogram showed occluded index TIPS (a). Balloon dilatation of the tissue between portal and cava (b). Portography before insertion of PS delineates the PV branches (c). Final portogram after PS creation showed good flow through the PS with shunting of blood to cava. CT thin-MIP showed the PS and index stent and the later seen longer inside the PV than the PS (e)

patients and Fluency stent in the remaining 8 patients. They reported that the creation of PS was technically successful in all patients. The PSG dropped significantly from $25.5 \pm 7.3 \mathrm{mmHg}$ to $10.9 \pm 2.3 \mathrm{mmHg}$. The duration of follow-up was $16.7 \pm 10.8$ months. The primary shunt patency rates at 12 months after the creation of PS was $70 \%$ with Wallstent and $87.5 \%$ with Fluency endoprostheses [21].

In our study, median duration of patency was 16 months while the patency rates at 12 and 18 months were $86.4 \%$ and $77.7 \%$, respectively. The patency rates of our series are higher than those mentioned in other comparable studies of the literature [18, 19, 21], although most of our patients $(89.8 \%)$ were Budd-Chiari syndrome due with additional thrombophilic nature. We assume that this higher patency rate was attributed to many factors. The first factor is the use double anti- platelets and anti-coagulants given for all patients. Siegerstetter et al. reported a higher patency rate for the group using ticlopidine with heparin compared to heparin alone [23]. The second factor is the entry through the left PV or its neck. Either point of entry allows straight course of the stents with no apparent curves. This prevents turbulence of blood flow and subsequent thrombosis of kinks. Our findings agree well with those reported by Chu et al., Chen et al., and Luo et al. These authors reported higher patency rates for TIPS on the left compared to the right PV [24-26].

Regarding the complications, no death was recorded. Although we inevitably punctured the biliary duct with suspected hemobilia in 2 patients, there were no signs or symptoms of biliary obstruction. Bleeding occurred in 3 patients $(8.1 \%)$ due to excessive trials to puncture the PV branches inside the liver. Other intra-procedure

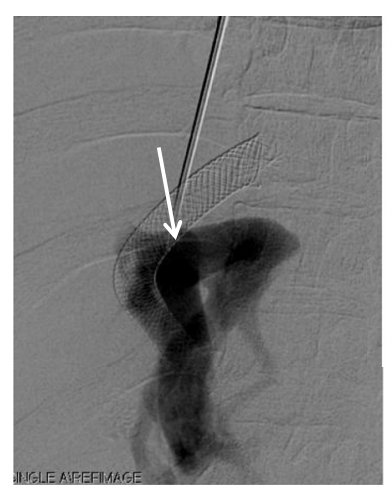

a

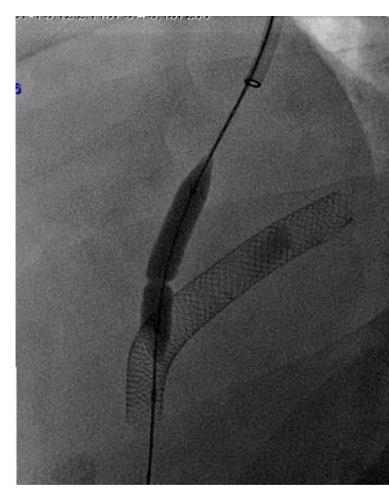

b

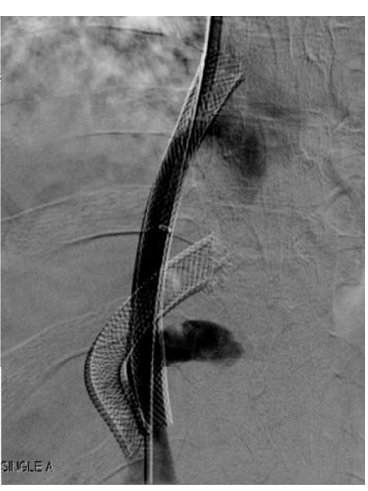

c

Fig. 7 A 55-year-old male with cirrhotic liver and occluded index TIPS. Puncture of the portal vein was done from the neck of the PV (arrow), and portogram (a) shows occluded index TIPS where no contrast passing through it. Balloon dilatation of the parenchyma is seen in (b). Final portogram after insertion of the PS showed good contrast opacification of the shunt with good shunting of contrast from portal to cava (c) 
Table 2 Patency parameters of the parallel shunt

\begin{tabular}{ll}
\hline Parameter & \\
\hline Mean duration of follow-up (months) & $26.8 \pm 8(22-45)$ \\
Median duration of patency (months) & $16(19-9)$ \\
PS dysfunctions during follow-up (months) & $8(11.2 \%)$ \\
Number of re-interventions & 10 \\
Mean interval of PS to first dysfunction (months) & $11.8 \pm 7.8$ \\
12 months primary patency rate & $32 / 37(86.4 \%)$ \\
18 months primary patency rate & $30 / 37(77.7 \%)$ \\
Causes of PS dysfunctions in follow-up period & \\
Thrombosis $(n)$ & 5 \\
PS stenosis $(n)$ & 3 \\
\hline
\end{tabular}

complications noted were respiratory distress and bradycardia that may be due to manipulation of the occluded stents with minor PE. It is noteworthy that the presence of the index stent in the liver tissue limits the manipulations of TIPS needle to target the PV. Liver function remained stable and no recorded encephalopathy or hepatocellular carcinomas.

Our study has some limitations. The first limitation is the short term follow-up with a mean follow-up of only $26.8 \pm 8$ months. The second one is the retrospective design of our study. The third limitation is the lack of a control group to compare the behavior of dysfunction between index and PS groups.

\section{Conclusion}

It is proven from this study that patients with refractory TIPS occlusion have another chance for a second PS to treat portal hypertension symptoms. Although PS insertion is technically difficult requiring tricky manipulations, it is a durable, safe, and effective treatment for portal decompression on mid-term basis.

Table 3 Intra-procedure and early complications of PS

\begin{tabular}{ll}
\hline Complications & (n) (\%) \\
\hline Intra-procedure complications & $29(78.4 \%)$ \\
None & $3(8.1 \%)$ \\
Bleeding & $2(5.4 \%)$ \\
Biliary puncture & $1(2.7 \%)$ \\
Acute TIPS thrombosis & $1(2.7 \%)$ \\
Bradycardia & $1(2.7 \%)$ \\
Respiratory distress & \\
Early complication & $4(10.8 \%)$ \\
Acute TIPS thrombosis & \\
Late complications & \\
Encephalopathy & \\
Hepatocellular carcinoma & \\
Acute liver failure &
\end{tabular}

\section{Abbreviations}

CP: Caval pressure; PS: Parallel shunt; PSG: Porto-systemic gradient; PVP: PV pressure; PV: PV; TIPS: Transjugular intrahepatic shunt

\section{Acknowledgements}

We acknowledged Dr. Einas Maged, Lecturer of community medicine, National Liver Institute for helping with the statistical analysis of the study.

\section{Authors' contributions}

MA put the conception and design of the study, wrote the protocol, and was the radiologist who performed all the parallel shunt procedures as well as the index TIPS under revision. He contributed in reviewing of medical records, collecting and tabulating data, and selecting figures of the study. In addition, he also contributed in the data curation, formal analysis, methodology, manuscript writing, and approved the draft. HE contributed in the clinical follow-up of the cases at the time of parallel shunt insertion. He reviewed the medical records and collected data with manuscript drafting and approved the draft. MM contributed in the clinical follow-up of the case with endoscopic evaluation at the time of index TIPS and parallel shunt insertion. He reviewed medical records and collected data of the patients with manuscript drafting and approved the draft. AM contributed in the clinical follow-up of the cases at the time of TIPS. He reviewed the medical records and collected data of the patients with manuscript drafting. He also contributed in manuscript drafting and approved the draft. Finally and collectively, all authors have read and approved the manuscript.

\section{Funding}

No funding was received for this study.

\section{Availability of data and materials}

All data and materials are available when needed.

\section{Ethics approval and consent to participate}

This study was approved by the Research Ethics Committee of the National Liver Institute at Menoufia University in Egypt NLI IRB protocol number 00215/2020 (name of IRB, NLI IRB 00003413). All patients' consent to participate in this research was waived as it is a retrospective study.

\section{Consent for publication}

Being a retrospective study, patients' consent to publish the data contained within this study has been waived by the ethical committee.

\section{Competing interests}

The authors or author's institutions have no conflicts of interest which include financial or personal relationships that inappropriately influence their actions.

\section{Author details}

${ }^{1}$ Department of Diagnostic and Interventional Imaging, National Liver Institute, Menoufia University, Yassin Abdelghaffar St., Shebin Al-Kom, Menoufia, Egypt. ${ }^{2}$ Hepatology Department, National Liver Institute, Menoufia University, Shebin Al-Kom, Egypt.

Received: 30 August 2020 Accepted: 14 October 2020

Published online: 14 November 2020

\section{References}

1. Boyer TD, Haskal ZJ (2010) American Association for the Study of Liver Diseases. The role of transjugular intrahepatic portosystemic shunt (TIPS) in the management of portal hypertension: update 2009. Hepatology 51:306

2. Richter GM, Palmaz JC, Nöldge G, Rössle M, Siegerstetter V, Franke M, et al. The transjugular intrahepatic portosystemic stent-shunt. A new nonsurgical percutaneous method]. Radiologe 1989;29:406-411

3. Haskal ZJ, Pentecost MJ, Soulen MC, Shlansky-Goldberg RD, Baum RA, Cope C (1994) Transjugular intrahepatic portosystemic shunt stenosis and revision: early and midterm results. AJR Am J Roentgenol 163:439-444

4. Saxon RS, Ross PL, Mendel-Hartvig J, Barton RE, Benner K, Flora K et al (1998) Transjugular intrahepatic portosystemic shunt patency and the importance of stenosis location in the development of recurrent symptoms. Radiology 207:683-693 
5. Nishimine K, Saxon RR, Kichikawa K, Mendel-Hartvig J, Timmermans HA, Shim HJ et al (1995) Improved transjugular intrahepatic portosystemic shunt patency with PTFE-covered stent-grafts: experimental results in swine. Radiology 196:341-347

6. Tanihata H, Saxon RR, Kubota Y, Pavcnik D, Uchida BT, Rosch J et al (1997) Transjugular intrahepatic portosystemic shunt with silicone-covered Wallstents: results in a swine model. Radiology 205:181-184

7. Cura M, Cura A, Suri R, El-Merhi F, Lopera J, Kroma G (2008) Causes of TIPS dysfunction. AJR Am J Roentgenol 191:1751-1757

8. Weber NC, Nadolski JG et al (2015 Sep) Long-term patency and clinical analysis of expanded polytetra-fluoroethylene-covered transjugular intrahepatic portosystemic shunt stent grafts. J Vasc Interv Radio 26(9): 1257-1265 quiz 1265

9. Luo X, Zhao M, Wang X et al (2019) Long-term patency and clinical outcome of the transjugular intrahepatic portosystemic shunt using the expanded polytetrafluoroethylene stent-graft. PLoS One. 14(2):e0212658

10. Chan CY, Liang PC (2010) Recanalization of an occluded intrahepatic portosystemic covered stent via the percutaneous transhepatic approach. Korean J Radiol 11:469-471

11. Chen SL, Xiao CJ, Wang S, Jin S, Zhao J, The pull-through technique for recanalization of transjugular intrahepatic portosystemic shunt dysfunction, Research G, Volume P (2020) Article ID:9150173, 7 pages

12. Spiliopoulos S, Kamarinos NV, Konstantos C et al. Recanalization of occluded transjugular intrahepatic portosystemic shunts using the Rösch-Uchida stiffening cannula; CardioVascular and Interventional Radiology volume 41, pages799-803(2018)

13. Cejna M, Peck-Radosavljevic M, Thurnher SA et al (2001) Creation of transjugular intrahepatic portosystemic shunts with stent-grafts: initial experiences with a polytetrafloroethylene-covered nitinol endoprosthesis. Radiology 221:437-446

14. Ochs $A$, Rössle $M$, Haag $K$, Hauenstein $K H$, Deibert $P$, Siegerstetter $V$ et al (1995) The transjugular intrahepatic portosystemic stent-shunt procedure for refractory ascites. N Engl J Med 332:1192-1197

15. Rössle M, Gerbes AL (2010) TIPS for the treatment of refractory ascites, hepatorenal syndrome and hepatic hydrothorax: a critical update. Gut 59: 988-1000

16. Clark TW, Agarwal R, Haskal ZJ, Stavropoulos SW (2004) The effect of initial shunt outflow position on patency of transjugular intrahepatic portosystemic shunts. J Vasc Interv Radiol 15(2 Pt 1):147-152

17. Luo X, Nie L, Tsauo J et al (2013) Parallel shunt for the treatment of transjugular intrahepatic portosystemic shunt dysfunction. Korean J Radiol 14(3):423-429

18. Dabos KJ, Stanley AJ, Redhead DN, Jalan R, Hayes PC (1998) Efficacy of balloon angioplasty, restenting, and parallel shunt insertion for shunt insufficiency after transjugular intrahepatic portosystemic stent-shunt (TIPS S). Minim Invasive Ther Allied Technol 7:287-293

19. Helmy A, Redhead DN, Stanley AJ, Hayes PC (2006) The natural history of parallel transjugular intrahepatic portosystemic stent shunts using uncovered stent: the role of host-related factors. Liver Int 26:572-578

20. Raissi D, Yu Q, Nisiewicz M (2019 February 27) Krohmer S; Parallel transjugular intrahepatic portosystemic shunt with Viatorr ${ }^{\circledast}$ stents for primary TIPS insufficiency: case series and review of literature. World J Hepatol 11(2):217-225

21. Larson M, Kirsch D (2016) Kay D; Parallel transjugular intrahepatic portosystemic shunt (TIPS) in the setting of TIPS occlusion. Ochsner Journal 16:113-115

22. Rathod K, Popat B, Barai P, Amrapurkar D (2016) Parallel transjugular intrahepatic portosystemic shunt (TIPS) creation in a patient with a preexisting unsalvageable occluded TIPS and refractory variceal bleeding. J Clin Interv Radiol 1:40-42

23. Siegerstetter V, Huber M, Ochs A, Blum HE, Rössle M (1999) Platelet aggregation and platelet-derived growth factor inhibition for prevention of insufficiency of the transjugular intrahepatic portosystemic shunt: a randomized study comparing trapidil plus ticlopidine with heparin treatment. Hepatology 29:33-38

24. Chu J, Sun X, Piao L et al (2002) Portosystemic shunt via the left branch of PV for the prevention of encephalopathy following transjugular intrahepatic portosystemic shunt. Zhong hua Gan Zang Bing Za Zhi 10:437-440

25. Chen L, Xiao T, Chen W, Long Q, Li R, et al. Outcomes of transjugular intrahepatic shunt through the left branch vs. the right branch of the PV in advanced cirrhosis; a randomized trial. Liver International (2009); 1101-1109
26. Luo HS, Chu GJ, Huang HE et al (2019 Mar 7) Targeted puncture of left branch of intrahepatic PV in transjugular intrahepatic portosystemic shunt to reduce hepatic encephalopathy. World J Gastroenterol 25(9):1088-1099

\section{Publisher's Note}

Springer Nature remains neutral with regard to jurisdictional claims in published maps and institutional affiliations.

\section{Submit your manuscript to a SpringerOpen ${ }^{\circ}$ journal and benefit from:}

- Convenient online submission

- Rigorous peer review

- Open access: articles freely available online

High visibility within the field

- Retaining the copyright to your article

Submit your next manuscript at $\boldsymbol{\nabla}$ springeropen.com 